\title{
LOW PERFORMANCE-RELATED PHYSICAL FITNESS LEVELS ARE ASSOCIATED WITH CLUSTERED CARDIOMETABOLIC RISK SCORE IN SCHOOLCHILDREN: A CROSS-SECTIONAL STUDY
}

original paper

() Wroclaw University of Health and Sport Sciences

DOI: https://doi.org/10.5114/hm.2022.107976

\author{
NERI SALDANHA FILHO ${ }^{1 \oplus}$, CÉZANE PRISCILA REUTER $^{1 \oplus,}$ \\ JOÃO FRANCISCO DE CASTRO SILVEIRA ${ }^{1,2}$, LETÍCIA BORFE $^{1,2} \oplus$, \\ JANE DAGMAR POLLO RENNER ${ }^{1 \oplus}$, HILDEGARD HEDWIG POHL ${ }^{1 \oplus}$ \\ ${ }^{1}$ University of Santa Cruz do Sul, Santa Cruz do Sul, Brazil \\ ${ }^{2}$ Federal University of Rio Grande do Sul, Porto Alegre, Brazil
}

\begin{abstract}
Purpose. The study aim was to verify if there were associations between performance-related physical fitness levels and the clustered cardiometabolic risk score among children and adolescents.

Methods. The cross-sectional study involved 1200 (655 females) children and adolescents aged 7-17 years. Performancerelated physical fitness levels (upper limb strength [ULS], lower limb strength [LLS], agility, speed, and cardiorespiratory fitness [CRF]) were evaluated and categorized as healthy or unhealthy levels. Waist circumference, systolic blood pressure, glucose, and blood lipoprotein (triglycerides, total cholesterol, and high-density lipoprotein cholesterol) were measured. The clustered cardiometabolic risk score constituted the sum of internationally-derived standardized values (z-scores) for each risk factor divided by 5 . Associations between performance-related physical fitness levels and the clustered cardiometabolic risk score were determined with linear regression models.
\end{abstract}

Results. Participants with healthy ULS levels exhibited a less favourable clustered cardiometabolic risk score, whereas healthy levels of LLS, agility (only in girls), and CRF (only in boys) were related with a more favourable clustered cardiometabolic risk score. ULS ( $\beta$ : -0.091 [95\% CI: $-0.120 ;-0.062])$, LLS ( $\beta$ : -0.272 [95\% CI: $-0.368 ;-0.177])$, and CRF ( $\beta$ : -0.218 [95\% CI: $-0.324 ;-0.112])$ were inversely associated with the clustered cardiometabolic risk score, while agility ( $\beta$ : 0.112 [95\% CI: 0.082; 0.142]) and speed ( $\beta$ : 0.079 [95\% CI: 0.039; 0.119]) demonstrated a positive association with the clustered cardiometabolic risk score.

Conclusions. Our results emphasize the importance of following moderate-to-vigorous physical activity guidelines to better develop physical fitness levels for the maintenance of cardiometabolic health during childhood and adolescence.

Key words: adolescent, child, health, metabolic syndrome, physical fitness, students

\section{Introduction}

The simultaneous increase of risk factors as behavioural habits and metabolic disorders characterizes the metabolic syndrome (MetS) [1]. The majority of children and adolescents do not present chronic outcomes related to MetS, but they are already in the initial stages of MetS risk factors development [2]. These risk factors are metabolic disorders such as higher levels of triglycerides and total cholesterol, hypertension, body composition, insulin resistance, and lower levels of high-density lipoprotein cholesterol. Additionally, the literature includes such behavioural habits as low health-related physical fitness levels on the risk factor list [3]. It has been reported that these risk factors for MetS start early in childhood [4], and they can track into adulthood [5].

MetS among children and adolescents has been widely investigated by using a clustered cardiometabolic risk score [2]. It is considered more efficient to verify the effective risk for cardiovascular diseases compared with traditional MetS diagnosis criteria because

Correspondence address: Cézane Priscila Reuter, Department of Health Sciences, University of Santa Cruz do Sul, Av. Independência, 2293 - Zip code: 96816-501, Bairro Universitário, Santa Cruz do Sul, Rio Grande do Sul, Brazil, e-mail: cezanereuter@unisc.br, https://orcid.org/0000-0002-4549-3959

Received: June 24, 2020

Accepted for publication: February 14, 2021

Citation: Saldanha Filho N, Reuter CP, de Castro Silveira JF, Borfe L, Renner JDP, Poh HH. Low performance-related physical fitness levels are associated with clustered cardiometabolic risk score in schoolchildren: a cross-sectional study. Hum Mov. 2022;23(3):113-119; doi: https://doi.org/10.5114/hm.2022.107976. 
it comprises as much information concerning the risk factors as possible, with the consideration of the traditional risk factors for cardiovascular diseases, to construct a composite score [6].

Previous studies reported that low levels of healthrelated physical fitness components were associated with less favourable levels of cardiometabolic risk factors. Moreover, it is established that there is an inverse association with the clustering of cardiometabolic risk [7-9]. In agreement with those findings, active children and adolescents seem to be less likely to present an unhealthy cardiometabolic profile [10] once the physical activity practice positively affects overall health, the cardiorespiratory, metabolic, and musculoskeletal systems [11], and motor competence, which directly influences the performance-related physical fitness levels [12].

Research has often demonstrated the relationship between health-related physical fitness and the clustered cardiometabolic risk; as far as we know, however, this is the first study involving a Brazilian sample to investigate performance-related physical fitness levels with the clustered cardiometabolic risk score among childhood and youth. Furthermore, one can assume that the cardiometabolic risk develops when children and adolescents exhibit low performance-related physical fitness levels. This assumption becomes important since motor competence is closely related to daily physical activities and sport practice. The present study aimed to verify if there were associations between performancerelated physical fitness levels and the clustered cardiometabolic risk score among children and adolescents.

\section{Material and methods}

\section{Participants and study design}

This cross-sectional study involved a sample composed of 1200 children and adolescents (655 females) aged 7-17 years from public and private schools of Santa Cruz do Sul, Brazil. The present research is part of a larger survey named 'Schoolchildren's Health Phase II'.

The study was carried out in 25 randomly selected schools in Santa Cruz do Sul municipality, which has a total of 50 registered schools and a population of 20,380 students. The data collected represent the entire municipality (urban and rural areas), in view of the density of schoolchildren population in each region (centre, north, south, east, and west). The sample power calculation was performed by using the $G^{*}$ Power 3.1 program (Heinrich-Heine-Universität, Düsseldorf, Ger- many). A minimum of 655 students were stipulated, with the consideration of a test power of $(1-\beta)=0.95$, a significance level of $\alpha=0.05$, and an effect size of 0.30 , as suggested by Faul et al. [13] for the Poisson regression analysis (presence vs. absence of cardiometabolic risk as a dependent variable).

\section{Body composition and socioeconomic status assessment}

All evaluations were carried out in the University of Santa Cruz do Sul facilities by trained professionals. Body mass index (BMI) was calculated as the ratio between weight and height squared and classified as normal weight, overweight, or obesity [14]. The participants were categorized as having a low, medium, or high socioeconomic background as self-reported by using the Brazilian Economic Classification Criteria questionnaire [15].

\section{Performance-related physical fitness assessment}

The performance-related physical fitness levels were determined in accordance with the standards, criteria, and tests established by the Projeto Esporte Brasil (PROESP-BR) [16]. The following components were evaluated: (1) upper limb strength, verified through the medicine ball throw test; (2) lower limb strength, verified through the horizontal jump test; (3) agility, verified through the square test; (4) speed, verified through the 20-meter run test; and (5) cardiorespiratory fitness, verified through the 9-minute running and walking test. Data were categorized by the cut-off points established by PROESP-BR (weak, reasonable, good, very good, and excellent), with the consideration of sex and age, and dichotomized as: (1) unhealthy levels (weak or reasonable); and (2) healthy levels (good, very good, or excellent).

\section{Clustered cardiometabolic risk score}

The waist circumference (WC) was evaluated by using an inelastic plastic tape measure. The systolic blood pressure (SBP) was measured with the children sitting at rest, by using a sphygmomanometer (B-D ${ }^{\circledR}$, aneroid, Germany) with a cuff suitable for the children's arm circumference and a stethoscope (Premium, Rappaport, China). The levels of fasting glucose, triglycerides, total cholesterol (TC), and high-density lipoprotein cholesterol (HDL-C) were determined through blood collection, after 12-hour fasting, carried out with Miura 200 automated equipment (I.S.E., Rome, Italy) by 
using commercial DiaSys kits (DiaSys Diagnostic Systems, Germany).

Before analysis, skewed variables (WC, TC/HDL-C ratio, and triglycerides) were logarithmically transformed by the natural logarithm. The risk factors variables (WC, SBP, glucose, triglycerides, and TC/HDL-C ratio) were standardized in accordance with sex- and age-specific international reference values by using the following equation, suggested by Stavnsbo et al. [17]:

$$
\begin{gathered}
z \text {-score }=\left(\mathrm{X}_{\text {Observed Brazilian value }}-\mathrm{X}_{\text {Predicted mean }}\right) / \\
S D_{\text {International reference }}
\end{gathered}
$$

The clustered cardiometabolic risk score was derived by summing the SBP, WC, triglycerides, glucose, and TC/HDL-C ratio $z$-scores and dividing the value by 5 .

\section{Statistical analysis}

The Statistical Package for the Social Sciences (SPSS, version 23.0, IBM, Armonk, NY, USA) software was used for all statistical analyses. A descriptive analysis was performed to describe the Brazilian sample. The independent Student's $t$-test was applied to verify mean differences between sexes. The quantitative variables were also analysed by linear regression models considering the performance-related physical fitness levels as independent variables and the clustered cardiometabolic risk score as a dependent variable. Unstand- ardized and standardized coefficients ( $\beta$ ) with 95\% confidence intervals (CI) were presented. Preliminary analyses evaluated which confounders should adjust the models. The confounder variable tested should be associated with both the independent and dependent variables. The models were adjusted for BMI and socioeconomic status (more details within Table 3). The values of $p<0.05$ were considered significant in all analyses.

\section{Ethical approval}

The research related to human use has complied with all the relevant national regulations and institutional policies, has followed the tenets of the Declaration of Helsinki, and has been approved by the Committee of Ethics in Research with Human Subjects of the University of Santa Cruz do Sul, under protocol number 2959/2011.

\section{Informed consent}

Informed consent has been obtained from the parents of all individuals included in this study.

\section{Results}

Table 1 presents the descriptive characteristics of the participants. Regarding the performance-related physical fitness, boys performed better in all tests, and these differences were statistically significant $(p<0.05)$.

\begin{tabular}{|c|c|c|c|}
\hline \multirow{2}{*}{ Characteristics } & Boys $(n=545)$ & Girls $(n=655)$ & Total $(n=1200)$ \\
\hline & \multicolumn{3}{|c|}{ Mean $(S D)$} \\
\hline Upper limb strength (m) & $3.2(1.3)$ & $2.7(0.8)$ & $2.9(1.1)^{*}$ \\
\hline Lower limb strength (m) & $1.5(0.3)$ & $1.3(0.2)$ & $1.4(0.3)^{*}$ \\
\hline Agility (s) & $7.1(1.0)$ & $7.5(0.9)$ & $7.3(1.0)^{*}$ \\
\hline Speed (s) & $4.6(0.7)$ & $5.0(0.7)$ & $4.8(0.7)^{*}$ \\
\hline Cardiorespiratory fitness (km) & $1.42(0.30)$ & $1.17(0.20)$ & $1.28(0.28)^{*}$ \\
\hline \multirow[t]{2}{*}{ Clustered cardiometabolic risk score } & $0.06(0.63)$ & $0.09(0.62)$ & $0.07(0.63)$ \\
\hline & \multicolumn{3}{|c|}{$n(\%)$} \\
\hline \multicolumn{4}{|l|}{ Body mass index } \\
\hline Normal & 379 (69.5) & $488(74.5)$ & 867 (72.3) \\
\hline Overweight & $116(21.3)$ & $127(19.4)$ & $243(20.3)$ \\
\hline Obesity & $50(9.2)$ & $40(6.1)$ & $90(7.5)$ \\
\hline \multicolumn{4}{|l|}{ Socioeconomic status ${ }^{* *}$} \\
\hline A-B (high) & $300(55.0)$ & $346(52.8)$ & $646(53.8)$ \\
\hline $\mathrm{C}$ & $233(42.8)$ & $286(43.7)$ & $519(43.3)$ \\
\hline $\mathrm{D}-\mathrm{E}$ & $12(2.2)$ & $23(3.5)$ & $35(2.9)$ \\
\hline
\end{tabular}

Table 1. Descriptive characteristics of the participants

* difference between boys and girls verified with the independent Student's $t$-test $(p<0.05)$

** A-E scores in accordance with the Brazilian Economic Classification Criteria questionnaire 


\section{HUMAN MOVEMENT}

N. Saldanha Filho et al., Physical fitness and metabolic risk

Furthermore, the majority of the participants were from families with high socioeconomic status (53.8\%). Lastly, $20.3 \%$ and $7.5 \%$ of the sample were overweight and obese, respectively.

Table 2 shows high percentages of unhealthy levels for all 5 performance-related physical fitness components: upper limb strength $(47.2 \%$ in boys and $49.0 \%$ in girls), lower limb strength (78.2\% in boys and $64.1 \%$

Table 2. Comparison of the clustered cardiometabolic risk score between performance-related physical fitness levels

\begin{tabular}{llc}
\hline \multirow{2}{*}{ Factors } & \multicolumn{3}{c}{$\begin{array}{c}\text { Clustered cardiometabolic } \\
\text { risk score }\end{array}$} \\
\cline { 2 - 3 } & & \multicolumn{2}{c}{ Mean $(S D)$} & $p^{*}$ \\
\hline
\end{tabular}

\section{BOYS}

\begin{tabular}{lcrrr}
\hline Upper limb strength & & & \\
$\quad$ Healthy levels & $288(52.8)$ & $0.149(0.660)$ & $<0.001^{* *}$ \\
Unhealthy levels & $257(47.2)$ & $-0.043(0.583)$ & \\
\hline Lower limb strength & & & \\
$\quad$ Healthy levels & $119(21.8)$ & $-0.107(0.599)$ & $0.001^{* *}$ \\
Unhealthy levels & $426(78.2)$ & $0.104(0.633)$ & \\
\hline Agility & & & \\
Healthy levels & $106(19.4)$ & $-0.020(0.659)$ & 0.154 \\
Unhealthy levels & $439(80.6)$ & $0.077(0.624)$ & \\
\hline Speed & & & \\
Healthy levels & $25(4.6)$ & $-0.004(0.685)$ & 0.617 \\
Unhealthy levels & $520(95.4)$ & $0.061(0.629)$ & \\
\hline Cardiorespiratory fitness & & \\
Healthy levels & $234(42.9)$ & $-0.066(0.567)$ & $<0.001^{* *}$ \\
\hline & & & \\
\hline
\end{tabular}

\section{GIRLS}

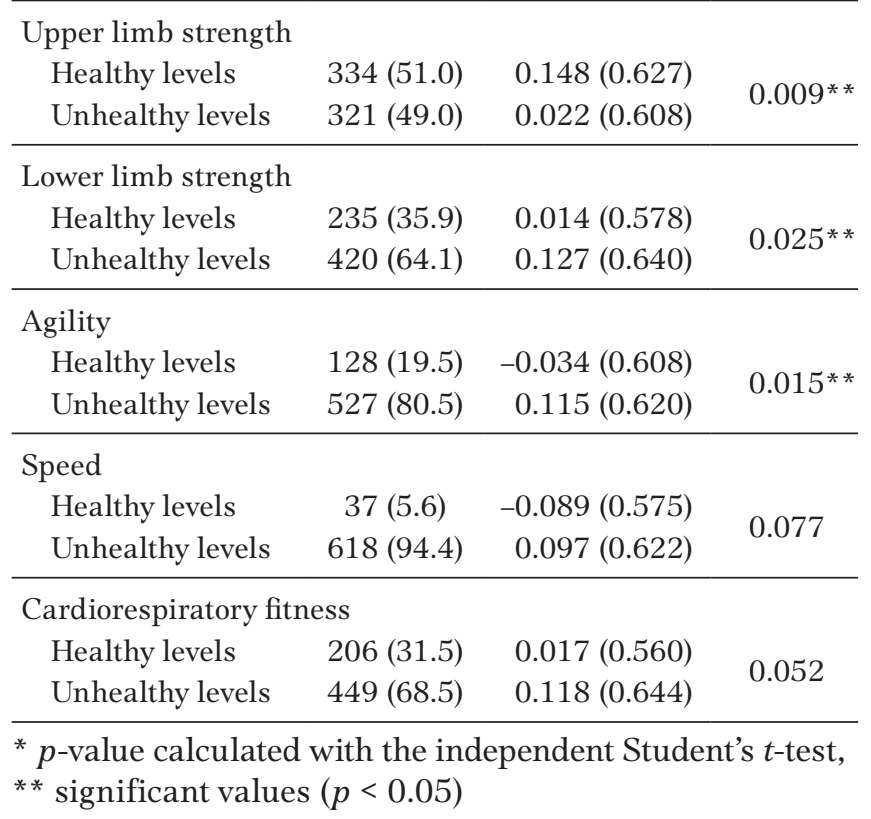

in girls), agility (80.6\% in boys and $80.5 \%$ in girls), speed (95.4\% in boys and $94.4 \%$ in girls), and cardiorespiratory fitness (57.1\% in boys and $68.5 \%$ in girls). The table also presents the comparison of the clustered cardiometabolic risk score between performance-related physical fitness healthy and unhealthy levels. Among boys, participants with healthy levels of upper limb strength showed a less favourable clustered cardiometabolic risk score $(p<0.001)$, whereas those with healthy levels of lower limb strength $(p=0.001)$ and cardiorespiratory fitness $(p<0.001)$ exhibited a more favourable clustered cardiometabolic risk score. In girls, participants with healthy levels of upper limb strength showed a less favourable clustered cardiometabolic risk score $(p=0.009)$, whereas those with healthy levels of lower limb strength $(p=0.025)$ and agility ( $p=$ $0.015)$ presented a more favourable clustered cardiometabolic risk score.

The linear regression models (Table 3 ) indicated that the upper limb strength $(-0.091[-0.120 ;-0.062])$, lower limb strength $(-0.272[-0.368 ;-0.177])$, and cardiorespiratory fitness $(-0.218[-0.324 ;-0.112])$ were inversely associated with the clustered cardiometabolic risk score. Also, a positive association was determined of agility (0.112 [0.082; 0.142]) and speed (0.079 [0.039; 0.119]) with the clustered cardiometabolic risk score. Among girls, there were no associations of speed or cardiorespiratory fitness with the clustered cardiometabolic risk score.

\section{Discussion}

The present study demonstrated a high percentage of unhealthy levels of all physical fitness components in the sample. Overall, the high prevalence of unhealthy performance-related physical fitness levels is in line with the results obtained by Mello et al. [18] among 8750 Brazilian children and adolescents by using the PROESP-BR database. A recent tracking study conducted by True et al. [19] evaluating 9 measures of physical fitness at 5 time points throughout childhood to adolescence/young adulthood demonstrated the importance of developing healthy physical fitness early in life since physical fitness levels track into young adulthood for boys $(r: 0.29 ; 0.79)$ and girls $(r$ : $0.23 ; 0.89$ ); the same refers to the cardiometabolic risk factors from childhood to adolescence [20] and adulthood [5]. These findings suggest a potential future problem for our sample since being physically fit during childhood and adolescence is associated with a lower cardiometabolic risk later in life, as evidenced by a systematic review of longitudinal studies [21]. 
Table 3. Association between performance-related physical fitness and the clustered cardiometabolic risk score

\begin{tabular}{|c|c|c|c|}
\hline \multirow{2}{*}{ Factors } & \multicolumn{3}{|c|}{ Clustered cardiometabolic risk score } \\
\hline & $\beta(95 \% \mathrm{CI})$ & $\beta^{*}$ & $p$ \\
\hline \multicolumn{4}{|l|}{ All participants } \\
\hline Upper limb strength (m) & $-0.091(-0.120 ;-0.062)$ & -0.158 & $<0.001 * *$ \\
\hline Lower limb strength (m) & $-0.272(-0.368 ;-0.177)$ & -0.135 & $<0.001 * *$ \\
\hline Agility (s) & 0.112 (0.082; 0.142) & 0.175 & $<0.001 * *$ \\
\hline Speed (s) & $0.079(0.039 ; 0.119)$ & 0.094 & $<0.001 * *$ \\
\hline Cardiorespiratory fitness $(\mathrm{km})$ & $-0.218(-0.324 ;-0.112)$ & -0.098 & $<0.001 * *$ \\
\hline \multicolumn{4}{|l|}{ Boys } \\
\hline Upper limb strength (m) & $-0.077(-0.112 ;-0.041)$ & -0.160 & $<0.001 * *$ \\
\hline Lower limb strength (m) & $-0.337(-0.461 ;-0.213)$ & -0.184 & $<0.001 * *$ \\
\hline Agility (s) & 0.124 (0.080; 0.167) & 0.190 & $<0.001 * *$ \\
\hline Speed (s) & $0.113(0.055 ; 0.171)$ & 0.134 & $<0.001 * *$ \\
\hline Cardiorespiratory fitness $(\mathrm{km})$ & $-0.285(-0.428 ;-0.143)$ & -0.138 & $<0.001 * *$ \\
\hline \multicolumn{4}{|l|}{ Girls } \\
\hline Upper limb strength (m) & $-0.141(-0.200 ;-0.083)$ & -0.177 & $<0.001^{\mathrm{a} * *}$ \\
\hline Lower limb strength (m) & $-0.211(-0.375 ;-0.047)$ & -0.085 & $0.012 * *$ \\
\hline Agility (s) & $0.102(0.059 ; 0.146)$ & 0.154 & $<0.001^{\mathrm{a} * *}$ \\
\hline Speed (s) & $0.049(-0.011 ; 0.108)$ & 0.054 & 0.110 \\
\hline Cardiorespiratory fitness $(\mathrm{km})$ & $-0.161(-0.366 ; 0.045)$ & -0.052 & 0.126 \\
\hline
\end{tabular}

Linear regression model considering the performance-related physical fitness levels as independent variables and the clustered cardiometabolic risk score as a dependent variable $(p<0.05)$. All models adjusted for body mass index. $\beta^{*}$ - standardized coefficient

${ }^{a}$ model adjusted for body mass index and socioeconomic status, ${ }^{* *}$ significant values $(p<0.05)$

According to our results, performance-related physical fitness levels were associated with the clustered cardiometabolic risk score. Children and adolescents with healthy upper limb strength showed a less favourable clustered cardiometabolic risk score, whereas healthy levels of lower limb strength, agility (only in girls), and cardiorespiratory fitness (only in boys) implied more favourable clustered cardiometabolic risk scores. In turn, the linear regression models revealed an inverse association between upper limb strength and the clustered cardiometabolic risk score. These findings concerning the upper limb strength are not in concordance with evidence that demonstrates the preventive importance of a better muscular strength level during youth for overall and cardiometabolic health [22]. This might be attributable to methodological differences concerning muscular strength assessment: studies usually calculate $z$-scores from 2 or more muscular power measurements to obtain a muscular fitness variable. Also, the association between healthy upper limb strength and a less favourable clustered cardiometabolic risk score found in the present study could be explained by physical fitness differences depending on the body composition. Lopes et al. [23] investigated levels of upper and lower limb strength among obese and non-obese adolescents. Their results demonstrated that obese individuals outperformed the non-obese ones in both muscular strength tests. Additionally, the higher body composition levels assessed by the BMI equation and the bioelectric impedance method were directly and significantly correlated with both upper and lower limb strength.

With respect to the other performance-related physical fitness components, the linear regression models showed that lower limb strength and cardiorespiratory fitness were inversely associated with the clustered cardiometabolic risk score for all participants, whereas agility and speed presented a positive association with the clustered cardiometabolic risk score. These results demonstrate that the better the performance-related physical fitness components are, the more favourable the clustered cardiometabolic risk score seems to be. Zaqout et al. [7], in a 2-year longitudinal study with 1635 European children aged 6-11 years, observed a similar association between all performance-related physical fitness components evaluated and the clustered cardiometabolic risk score, except for the upper limb strength (which slightly 
contrasts with the current study). On the basis of this evidence, children and adolescents should be encouraged to follow moderate-to-vigorous physical activity guidelines to better develop their motor competence skills and, consequently, their performance-related physical fitness levels [24, 25].

The literature demonstrates that children with higher motor competence outperform those with lower motor competence in physical fitness tests [12]. This cause and effect relationship could be explained by the fact that children who are more physically active have more chances to develop their motor skills and, consequently, continue their participation in sports across growing [26], which could lead to a better future cardiometabolic profile [10]. Besides, for a better cardiometabolic health, it is important to present low body composition levels, and also healthy performancerelated physical fitness levels. An analysis between physical fitness components and cardiometabolic risk mediated by body composition variables demonstrated that higher physical fitness was associated with a more favourable cardiometabolic risk, particularly when it was also accompanied by a good body composition level [27, 28].

The present study has some strengths. The first one is the representative randomly selected sample of children and adolescents from a municipality of Southern Brazil. Secondly, a major strength is the use of common international reference values to standardize each of the cardiometabolic risk factors, as suggested by Stavnsbo et al. [17], rather than the traditional MetS diagnosis criteria. This is an accepted method for defining children's and adolescents' cardiometabolic health in the literature, more accepted than sample-specific methods to calculate $z$-scores. However, the present study also has some limitations that should be noted. The cross-sectional design makes it impossible to establish the cause and effect impact between the performance-related physical fitness components and the clustered cardiometabolic risk. The physical fitness levels during childhood and adolescence and the better future cardiometabolic profile hypothesized in our discussion remain an interesting theoretical construct, not fully supported by our data, which could and should be further tested within future studies with different methodological design approaches. Finally, the results may have been influenced by other potential confounding variables that were not available in the statistical analysis (e.g., moderate-to-vigorous physical activity level and the pubertal status).

\section{Conclusions}

In conclusion, the levels of performance-related physical fitness components were inversely associated with the cardiometabolic risk. Our results emphasize the importance of following moderate-to-vigorous physical activity guidelines to better develop physical fitness levels for the maintenance of cardiometabolic health during childhood and adolescence.

\section{Acknowledgements}

We would like to thank the students, their families, and their schools for agreeing to participate in our study. We are also grateful for the contribution of professor Dr. Miria Suzana Burgos (in memoriam) to our study and for her dedication to the 'Schoolchildren's Health' research. Finally, we would also like to thank for the support from the Coordination for the Improvement of Higher Education Personnel (CAPES), Brazil (Finance Code 001).

\section{Disclosure statement}

No author has any financial interest or received any financial benefit from this research.

\section{Conflict of interest}

The authors state no conflict of interest.

\section{References}

1. Andersen LB, Bugge A, Dencker M, Eiberg S, El-Naaman B. The association between physical activity, physical fitness and development of metabolic disorders. Int J Pediatr Obes. 2011;6(Suppl. 1):29-34; doi: 10.3109/ 17477166.2011.606816.

2. Andersen LB, Lauersen JB, Brønd JC, Anderssen SA, Sardinha LB, Steene-Johannessen J, et al. A new approach to define and diagnose cardiometabolic disorder in children. J Diabetes Res. 2015;2015:539835; doi: 10.1155/2015/539835.

3. Mišigoj-Duraković M, Sorić M, Matika D, Jukić I, Duraković Z. Which is more important for reducing the odds of metabolic syndrome in men: cardiorespiratory or muscular fitness? Obesity. 2016;24(1):238244; doi: 10.1002/oby.21264.

4. Fernandez-Jimenez R, Al-Kazaz M, Jaslow R, Carvajal I, Fuster V. Children present a window of opportunity for promoting health: JACC review topic of the week. J Am Coll Cardiol. 2018;72(25):3310-3319; doi: 10.1016/ j.jacc.2018.10.031.

5. Camhi SM, Katzmarzyk PT. Tracking of cardiometabolic risk factor clustering from childhood to adulthood. Int J Pediatr Obes. 2010;5(2):122-129; doi: 10.3109/ 17477160903111763.

6. Vanlancker T, Schaubroeck E, Vyncke K, Cadenas-Sanchez C, Breidenassel C, González-Gross M, et al. Com- 
parison of definitions for the metabolic syndrome in adolescents. The HELENA study. Eur J Pediatr. 2017; 176(2):241-252; doi: 10.1007/s00431-016-2831-6.

7. Zaqout M, Michels N, Bammann K, Ahrens W, Sprengeler O, Molnar D, et al. Influence of physical fitness on cardio-metabolic risk factors in European children. The IDEFICS study. Int J Obes. 2016;40(7):1119-1125; doi: 10.1038/ijo.2016.22.

8. Saldanha Filho N, Reuter CP, Renner JDP, Barbian CD, de Castro Silveira JF, de Borba Schneiders L, et al. Low levels of cardiorespiratory fitness and abdominal resistance are associated with metabolic risk in schoolchildren. J PediatrEndocrinol Metab. 2019;32(5):455460; doi: 10.1515/jpem-2018-0236.

9. Lang JJ, Larouche R, Tremblay MS. The association between physical fitness and health in a nationally representative sample of Canadian children and youth aged 6 to 17 years. Health Promot Chronic Dis Prev Can. 2019;39(3):104-111; doi: 10.24095/hpcdp.39.3.02.

10. Silva DR, Werneck AO, Collings PJ, Fernandes RA, Barbosa DS, Ronque ERV, et al. Physical activity maintenance and metabolic risk in adolescents. J Public Health. 2018;40(3):493-500; doi: 10.1093/pubmed/ fdx077.

11. Solomon A, Borodulin K, Ngandu T, Kivipelto M, Laatikainen T, Kulmala J. Self-rated physical fitness and estimated maximal oxygen uptake in relation to allcause and cause-specific mortality. Scand J Med Sci Sports. 2018;28(2):532-540; doi: 10.1111/sms.12924.

12. Fransen J, Deprez D, Pion J, Tallir IB, D’Hondt E, Vaeyens R, et al. Changes in physical fitness and sports participation among children with different levels of motor competence: a 2-year longitudinal study. Pediatr Exerc Sci. 2014;26(1):11-21; doi: 10.1123/pes.2013-0005.

13. Faul F, Erdfelder E, Buchner A, Lang A-G. Statistical power analyses using $G^{*}$ Power 3.1: tests for correlation and regression analyses. Behav Res Methods. 2009; 41(4):1149-1160; doi: 10.3758/BRM.41.4.1149.

14. Cole TJ, Flegal KM, Nicholls D, Jackson AA. Body mass index cut offs to define thinness in children and adolescents: international survey. BMJ. 2007;335(7612): 194-197; doi: 10.1136/bmj.39238.399444.55.

15. Associação Brasileira de Empresas de Pesquisa. Brazilian economic classification criteria [in Portuguese]. 2012. Available from: http://www.abep.org/criteriobrasil.

16. Projeto Esporte Brasil. Tests and evaluation manual [in Portuguese]. 2012. Available from: https://www.ufrgs. $\mathrm{br} / \mathrm{proesp} /$.

17. Stavnsbo M, Resaland GK, Anderssen SA, Steene-Johannessen J, Domazet SL, Skrede T, et al. Reference values for cardiometabolic risk scores in children and adolescents: suggesting a common standard. Atherosclerosis. 2018;278:299-306; doi: 10.1016/j.atherosclerosis.2018.10.003.

18. Mello JB, Kunst Nagorny GA, De Castro Haiachi M, Reis Gaya A, Araujo Gaya AC. Projeto Esporte Brasil: physical fitness profile related to sport performance of children and adolescents. Rev Bras Cineantropom Desempenho Hum. 2016;18(6):658-666; doi: 10.5007/ 1980-0037.2016v18n6p658.

19. True L, Martin EM, Pfeiffer KA, Siegel SR, Branta CF, Haubenstricker J, et al. Tracking of physical fitness components from childhood to adolescence: a longitudinal study. Meas Phys Educ Exerc Sci. 2021;25(1):2234; doi: 10.1080/1091367X.2020.1729767.

20. Silveira JF, Reuter CP, Welser L, Pfeiffer KA, Andersen LB, Pohl HH, et al. Tracking of cardiometabolic risk in a Brazilian schoolchildren cohort: a 3-year longitudinal study. J Sports Med Phys Fitness. 2021;61(7): 997-1006; doi: 10.23736/S0022-4707.20.11479-8.

21. García-Hermoso A, Ramírez-Vélez R, García-Alonso Y, Alonso-Martínez AM, Izquierdo M. Association of cardiorespiratory fitness levels during youth with health risk later in life: a systematic review and meta-analysis. JAMA Pediatr. 2020;174(10):952-960; doi: 10.1001/ jamapediatrics.2020.2400.

22. Stodden D, Sacko R, Nesbitt D. A review of the promotion of fitness measures and health outcomes in youth. Am J Lifestyle Med. 2017;11(3):232-242; doi: 10.1177/ 1559827615619577.

23. Lopes W, Leite N, Silva L, Moraes F, Consentino C, Araújo $\mathrm{C}$, et al. Influence of obesity on the upper and lower body muscular strength in adolescents [in Portuguese]. Rev Bras Ativ Fís Saúde. 2013;18(6):720729; doi: 10.12820/rbafs.v.18n6p720.

24. Barnett LM, Lai SK, Veldman SLC, Hardy LL, Cliff DP, Morgan PJ, et al. Correlates of gross motor competence in children and adolescents: a systematic review and meta-analysis. Sports Med. 2016;46(11):1663-1688; doi: 10.1007/s40279-016-0495-z.

25. Tabacchi G, Faigenbaum A, Jemni M, Thomas E, Capranica L, Palma A, et al. Profiles of physical fitness risk behaviours in school adolescents from the ASSO project: a latent class analysis. Int J Environ Res Public Health. 2018;15(9):1933; doi: 10.3390/ijerph15091933.

26. Henrique RS, Ré AHN, Stodden DF, Fransen J, Campos CMC, Queiroz DR, et al. Association between sports participation, motor competence and weight status: a longitudinal study. J SciMed Sport. 2016;19(10):825829; doi: 10.1016/j.jsams.2015.12.512.

27. Díez-Fernández A, Martínez-Vizcaíno V, Torres-Costoso A, Cañete García-Prieto J, Franquelo-Morales P, Sánchez-López M. Strength and cardiometabolic risk in young adults: the mediator role of aerobic fitness and waist circumference. Scand J Med Sci Sports. 2018; 28(7):1801-1807; doi: 10.1111/sms.13077.

28. Díez-Fernández A, Sánchez-López M, Mora-Rodríguez R, Notario-Pacheco B, Torrijos-Niño C, MartínezVizcaíno V. Obesity as a mediator of the influence of cardiorespiratory fitness on cardiometabolic risk: a mediation analysis. Diabetes Care. 2014;37(3):855862; doi: 10.2337/dc13-0416. 